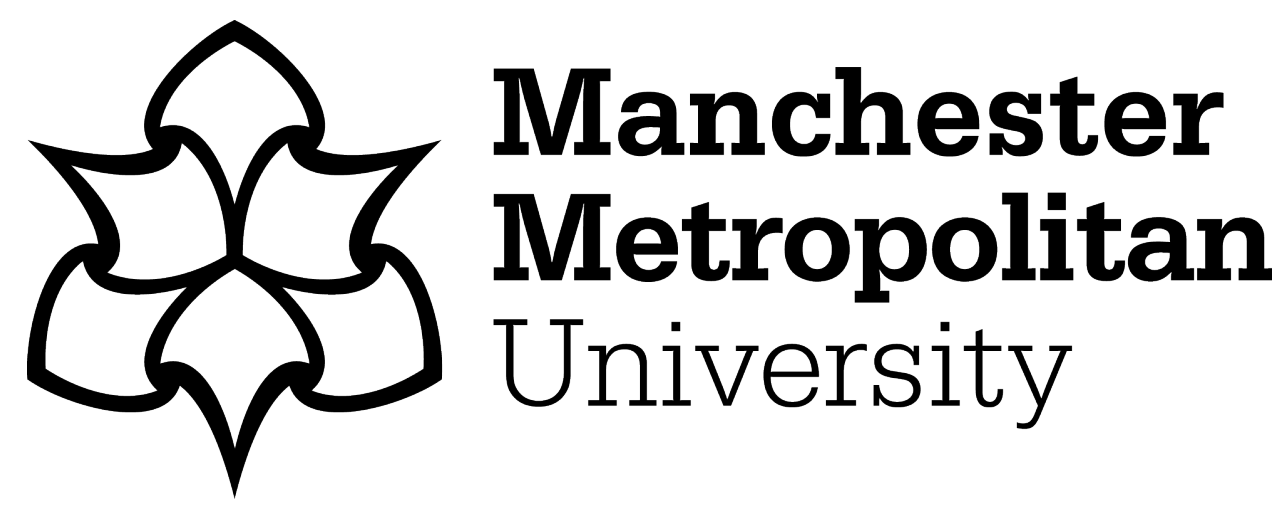

Paucar-Caceres, A and Jerardino-Wiesenborn, B (2020) A bridge for two views: Checkland's soft systems methodology and Maturana's ontology of the observer. Journal of the Operational Research Society, 71 (4). pp. 660672. ISSN 0160-5682

Downloaded from: https://e-space.mmu.ac.uk/622625/

Version: Accepted Version

Publisher: Taylor \& Francis

DOI: https://doi.org/10.1080/01605682.2019.1578629

Please cite the published version 


\title{
A bridge for two views: Checkland's Soft Systems Methodology and Maturana's Ontology of the observer
}

\begin{abstract}
Checkland and Maturana's work aim to understand and to improve problematic situations in organisations and in our everyday life. Maturana's phenomenological onto-epistemology (we are immersed in the praxis of living in an ontological multi-universe) seems to resonate with Soft Systems Methodology (SSM) interpretivist epistemology. We argue that this concurrence makes it possible to reflect and explore some of Maturana's ideas (structural determinism/structural coupling/organisational closure) when they are grafted into the phases of the Checkland's SSM seven-step process.

This paper aims to complement SSM by proposing a framework in which some key concepts from Maturana's Ontology of the Observer (OoO) might enhance and expand the understanding of the SSM application process.

An enriched and enhanced SSM process could have significant consequences in the Management Science/Operational Research (MS/OR) and Systems community practice. The framework proposed can have major social repercussions since it will incorporate the wellknown influential OoO ideas into MS/OR practice.
\end{abstract}

Keywords: Problem Structuring; Dialogue between two approaches; Soft Systems Methodology; Ontology of the Observer; Methodology enhancing

\section{Introduction}

Over the last two decades, developments in Management Science/Operational Research (MS/OR) have evidenced the emergence of multi-methodology, a practice that combines techniques, methods and methodologies from a variety of different systems thinking paradigms according to their perceived relevance in describing or dealing with any particular set of issues (Flood \& Jackson, 1991, Mingers 1997a, 1997b; Mingers and Brocklesby 1997; Jackson 1997, 1999). Such approaches combine methods from both the hard and soft systems spectrum, selecting the most relevant methods and techniques from each, as has been widely reported (Mingers 1997a; Munro and Mingers 2002; Brocklesby 1995; Brocklesby 1997; PaucarCaceres and Rodríguez-Ulloa 2007).

The multi-paradigm concept has certainly enhanced MS/OR, and systems practice. This trend however needs to be carefully considered, particularly when methods from different paradigms are mixed because in some combinations we might face a case of paradigm 
incommensurability. Certain combinations seem to be less problematic, particularly when their epistemologies seem to share common ground, for instance methodologies anchored in soft/interpretive and constructivist paradigms, and they both share certain assumptions in their anti-positivistic epistemological stance. This paper aims to contribute to the multimethodological MS/OR debate and practice by advancing a conversation between two systemic approaches underpinned by similar paradigms.

As has been widely reported in the management science and system literature, Soft Systems Methodology (SSM) fits under what is called the interpretivist paradigm, Jackson $(1982,1991$, 2003); Mingers (1984). The main tenets of this paradigm are that reality is complex, it is socially constructed; and a product of continuous people' interactions (interpretivist Ontology). Under this paradigm, the aim of any intervention is therefore to understand reality through interpretative process in which meaning is attributed (anti-positivist epistemology). No perspective exhausts the richness of reality or distorts the nature of things; each view is unitary not global.

Maturana and Varela's work on the nature of living, the biological nature of cognition and knowledge has been having far reaching influence on the systems and, various others fields, Maturana H, Varela F. (1980; 1987); Maturana (1988a, 1988b, 1997); Mingers (1995); Maturana and Bunnell (1997). Despite Maturana's own view that autopoiesis relates only to living systems, the theory of autopoiesis (ToA) seems to have acquired the status of general systems theory (Jackson 2000, cited by Reynolds, 2004). Along these lines, this paper aims to extend the use of Maturana's ideas in the field of management sciences by reflecting on these ideas to inform and complement Checkland's SSM process.

We argue that Checkland's SSM and Humberto Maturana's Ontology of the Observer (OoO) feature sufficient paradigmatic similarities to make a case for developing a bridge between these two approaches; a bridge in the form of a framework to look at both ways, a bridge paved with some of Maturana's concepts grafted into some of Checkland's 7-stages SSM process.

Following Reynolds (2004), we propose to use OoO concepts as metaphors or devices to shed light and overcome SSM shortcomings but endeavour to applying as much rigour as possible 
to avoid a 'naïve' application of OoO to SSM process. Also, in line with Brocklesby (2007), we aim to further explore the complementarity between SSM theoretical underpinnings (Vickers' epistemology enquiring systems) and Maturana's core ideas. We also concur with Brockelsby in that, by exploring this complementarity, we too aim 'to consider what theoretical and practical benefits there might be in terms of enhancing our understanding of the SSM process or improving its practice either by plugging gaps left by Vickers or through a more detailed understanding'. Brocklesby (2007: 162). As we aim to build a conversation between two systemic approaches, we argue that the consequences of using concepts derived from $\mathrm{OoO}$ will inform the conversation between Maturana's constitutive ontologies and SSM; and, in this way, bring a better understanding as to how MS/OR methodologies operate (Brocklesby and Mingers, 2005).

The paper is organized as follows: After this introduction, in section 2 we sketch the SSM process and outline some of its limitations. In section 3, we sketch concepts (structural determinism/structural coupling and organisational closure) of the underpinning Maturana's OoO argument and the ethical implications emerging from it. In section 4, using the 7-Stages SSM general framework, we re-visit SSM and propose a modified framework to enhance and strengthen the SSM intervention process. In Section 5, we advance our initial conclusions and discuss potential implications and consequences of using Maturana's ideas in an SSM intervention. Finally, in section 6, we provide some final reflections and suggest an agenda for further research.

\section{Soft Systems Methodology}

Peter Checkland's Soft Systems Methodology (SSM) is, arguably, the most developed systems methodology in terms of its theoretical premises and philosophical underpinnings. In the 1970s, Checkland and his colleagues at Lancaster University questioned the use of hard systems thinking to real-world situations and started to test a new methodology that shifted the systemicity from the real world to the process of enquiry itself. SSM articulates a learning process which takes the form of an enquiry process in a situation where people are concerned. This process leads to action in a never-ending learning cycle: once the action is taken, a new 
situation with new characteristics arises and the learning process starts again. In terms of social science, SSM holds an interpretative perspective:

[...] social reality is the ever-changing outcome of the social process in which human beings... continually negotiate and re-negotiate with others their perceptions and interpretations of the world outside themselves' Checkland, (1981: 283-284).

SSM is a process for managing in the broad sense: a process of achieving organised action. According to Checkland, the world is an ever-changing flux of events and ideas and 'managing' means reacting to that flux. We perceive, evaluate, and take action(s) which itself becomes part of this flux, leads to next perceptions and evaluations and, doing more actions and so on. It follows that SSM assumes that different actors of the situation will evaluate and perceive this flux differently, thus, creating issues through which the manager must be able to adjust for the organisation to cope with the ever-turbulent environment.

The basic structure of SSM rests on the idea that in order to tackle real-world situations, we need to make sure that the 'real-world' is separated from the 'systems thinking world'. This distinction is crucial for SSM because it guarantees that we will not see systems 'out there', SSM urges us to consider 'systems' as abstract concepts whose use can eventually help us to bring some improvements to the situation concerned. SSM takes reality to be problematical and ceases to worry about modelling it systemically. SSM seeks to work with different perceptions of reality, facilitating a systemic process of learning in which different viewpoints are examined and discussed in a manner that can lead to purposeful action in pursuit of improvement. SSM provides a systemic methodology by which participants learn what changes are feasible and desirable given the peculiarities of their problem situation.

SSM best known 7-stages process has been reported in numerous studies elsewhere. There no room in this article to enter in details. SSM learning process starts when a problem situation is perceived and somehow structured Checkland (1981, 1999). From this perception, the stakeholders, will select relevant systems and express them in basic root definitions (RD). A model building construction follows as means for predication of conceptual models. All activities of a purposeful action are carried out by individuals in the form of a Human Activity System (HAS). These then will be compared with the perceived situation before taking action. Throughout this paper when grafting SSM into Maturana onto-epistemology, we will refer to 
the SSM 7-steps ${ }^{1}$.

SSM encourages a participative approach, a learning process in which systems ideas are used to make sense of complex situations, and participation is crucial to gain a better understanding of the situation. All of this is well argued theoretically but its critics argue that, when it comes to the practice of applying SSM principles, little is given to the participants as to how to engage stakeholders. Deciding how to involve participants is left to the skills of the practitioner and as Jackson points out:

Participation is of considerable importance in SSM, especially at stages 5 and 6 (comparison stage) between conceptual models and what is perceived to exist in the real-world are being made, and feasible and desirable changes agreed. Checkland, however, does not address the issue of how far the participation should run or offer ground rules for what is to count as 'genuine' participation. Jackson (2003).

In general, the bulk of the criticism is about SSM lack of 'ground rules' to tackle the issue of power. When power is not equally distributed (which is, arguably, the most frequent case), SSM does not provide any rules as to how to negotiate these issues and the "structured debate" that SSM proposed seems to be dominated by those with capacity to dominate the discussions and to have their own priorities reflected in the outcome.

Although the critique from Jackson seems to be fair, SSM advocates would argue that, to some extent, SSM commitment to its constitutive rules that is keep its status a methodology (set of guidelines) rather than to be seen as a structured clear cut method, naturally prevented Checkland providing the set of ground rules that Jackson requests. Checkland was very cautious not to have SSM process interpreted in a normative fashion and consequently disrupt the spirit of the methodology as it was intended.

In this paper, we argue that a middle way can be achieved at least at conceptual level by providing a framework in which Maturana's ideas can indeed help to enhance and complement the use of SSM. We hope the initial exploration of grafting Maturana's concepts and the consequences of his powerful thinking not only give insights as to how to enrich the SSM

\footnotetext{
1 We decided to use SSM-Mode 1 (7-stages) rather than SSM-Mode 2 because we think the 7-Stages process makes easier to locate the $\mathrm{OoO}$ concepts along each of the phases. To locate these concepts along the Logical/Cultural stream (SSM-Mode 2) is also possible but it may be a more difficult to visualise.
} 
process; but will encourage researchers to venture similar conversations between the OR rich interpretive set of approaches with ideas or concepts emerging from approaches close to the constructivist

camp.

\section{Maturana's Ontology of the Observer: Structural Determinism and Organisational Closure}

Maturana and Varela's $(1980,1987)$ ToA describes living systems as self-producing (autopoietic) systems. The ToA and allied theories of biology of cognition describe in detail the mechanism by which a living system continually produces its own components which are then involved with the same production processes. As it is known, Maturana started with two seemingly separate questions: (1) What takes place in the phenomenon of perception; and (2) what is the organisation of the living? His illuminating conclusion was that the two phenomena -cognition and the process of living - are actually the same. So, for Maturana 'Cognition is a biological phenomenon and can only be understood as such; any epistemological insight into the domain of knowledge requires this understanding' (Maturana \& Varela, 1980: 7) and he equates cognition with living, stating that to know has become to live and, to live has become to know. Maturana's central feature of his understanding of the living is that: "it is the circularity of its organisation that makes the living system a unit of interactions, and it is this circularity that it must maintain in order to remain a living system" (Maturana \& Varela, 1980: 9). Self-producing systems are essentially autonomous systems and this feature is guaranteed through existing as self-producing systems.

That said, Maturana is and Varela was very reluctant to extend the application of the ToA outside the scope in which the notion of autopoiesis was formulated, that is, within the context of the explanation of life in its unicellular terms (Maturana \& Varela 1994:52). We concur with this view and, following Reynolds (2004), we propose to use OoO concepts as metaphors or devices (useful to shed light and converse with SSM practitioners), as opposed to considering SSM's human activity systems as autopoietic systems.

As it is well known, Maturana uses the term "organisation" and "structure" in a particular way: For Maturana, Organisation denotes the relations between components that gives a system its identity (that makes it a member of a particular type of system); whereas structure denotes the 
specific components and relationships, between components that actually constitute a particular unity and make its organisation real. The structure interacts with the medium and can change. The organisation is realized through the structure and as long the structural changes maintain the organisation, the system's identity remains (Maturana \& Varela 1987, Mingers, 1995). Since the aim of this paper is to build a conversation between two systemic approaches, we argue that the consequences of using these concepts in this particular way, will inform the conversation between Maturana's ToA and a Soft OR/MS methodology. This will produce a dialogue that can bring better understanding as to how MS/OR methodologies operate and how they can be better managed (Brocklesby and Mingers, 2005).

We are aware that the concepts outlined above form part of the earlier of Maturana's work developed in the $70 \mathrm{~s}$. In the $80 \mathrm{~s}$, Maturana incorporated these ideas and developed a more extensive, comprehensive and sophisticated onto-epistemological framework. These ideas form part of what Maturana calls the path of constitutive ontologies (Maturana 1988a).

Below, we explain, Maturana's $\mathrm{OoO}$ as the authors understand it and as it was used in the context of this paper. However, it is worth to indicate that in this paper we can only refer very briefly to Maturana's constitutive ontology of the observer. We encourage the reader to acquaint themselves with Maturana's original articles. This is our understanding of OoO:

Although Maturana is not interested in an independent metaphysical reality, he is deeply concerned with ontology (the dealing with the nature of being). Maturana (1988a) points out that the central issue facing humanity today is the question about what reality is. In fact, how we bringing forth, in the course of our lives as human beings, depends on how we answer the question about what reality is.

The OoO establishes that reality cannot be identified as an independent world from the observer; and the same time states that the observer is the necessary constitutive condition for the existence of anything. Furthermore, what we call real emerges as an interaction between an observer and an environment in a recursive and recurrent dynamic that Maturana calls the praxis of living in language. In other words, reality depends on what the observer as a living system does and all knowledge occurs as a product of the operations of distinctions that arise 
in the praxis of living in language. Consequently, OoO recognises the observer as a living system who lives in a multiverse that is the basis of the explanatory paths of constitutive ontologies. That is why, for Maturana, reality have an epistemological interest, because the question that he is finally interested in answering is: How do we do what we do as we observe our doing?

But as we mentioned above, there is no place here to further dwell in these developments; a full account of OoO can be found at Maturana \& Varela 1987; Maturana 1988a, 1988b, 1997; Maturana \& Poerksen 2004; Maturana, \& Dávila 2008, 2015. In the next section, we sketch the basic ideas contained in Maturana's onto-epistemology and concentrate on the implications that will be useful for the framework proposed in this paper.

\subsection{Ontological domains and the role of the observer}

According to Maturana, the question of "what is reality" is the most important question humanity faces (Maturana, 1988a). In fact, how we respond to that question has ontological and epistemological implications. The answer takes different paths depending on whether or not we consider the observer as a biological entity. To consider the observer as a biological entity, according to Maturana, implies accepting that when we experience we cannot distinguish between illusion and perception. In fact, we can only confirm that what happened to us was an illusion, only when we contrast that illusory experience with a new one (a posteriori).

In this regard, two comments are pertinent: On the one hand, are we always able to contrast the experience we are having with a new one? Clearly, in the flow of living, we are not always going to and from one experience to another. On the other hand, the new experience makes evident to us that what was experienced was an illusion, even though the new experience, is subject to the same conditions of previous experience that we have declared an illusion. This is the biological basis that points us to the impossibility of having access to a reality independent of the one who observes it, mediated by his/her biological structure.

Then it follows that all knowledge is not the result of having an objective ability to perceive the real world as it is. On the contrary, it is the result of a structural coupling, which implies a 
structural change and, which occurs as a dynamic and recurrent interaction between a living system (observer) and the environment in which he or she are immersed. Both the medium and the flow of the internal dynamics themselves trigger structurally determined changes in the observer. This has important consequences for the learning process: the ability to learn lies in the plasticity of the observer (specifically his nervous system), to compensate the perturbations from the environment that trigger structural changes that make possible structural coupling with their environment.

The experience of an observer is a priori to the experience of explaining any phenomenon in which the observer is involved. In this dynamic, experience as a praxis of living in language (first-order experience), does not need explanations or justifications, that is to say, that we can live without them. However, explanations occur in the praxis of living and, as such, they are also experiences which Maturana calls: second-order experiences (Maturana, 1988a). This is because they are reflections of the observer in his or her praxis of living in language about his or her praxis of living. In other words, the explanations of the experience are given in a different phenomenological domain than one in which the experience takes place. As we will see later on, Checkland's SSM echoes this position where a deliberate distinction is made between the real world (the world of the observers' experience) and the conceptual world (a world in which the observer reflects about the real world).

\subsection{Living in the domain of mutual acceptance/constitutive ontologies}

The well-known, short and seemingly simple phrase by Maturana and Varela is at the base of OoO: "Everything said is said by someone" (who can be him or herself). (Maturana \& Varela 1987: 27). Maturana argues that we as observers when we live in our praxis of living and when we are faced with the task of explaining that praxis, we can chose to follow one of two paths. These are either in a domain of transcendental ontologies (independent of the observer and what he/she does) - or a domain of constitutive ontologies (observer is part of what he/she observes and dependent on what he/she does). What makes it possible for an observer to locate $\mathrm{him} /$ her self in one or another ontological domain is the emotion that is at the base of the praxis of living in language. Indeed, the emotion that allows the other to arise as a legitimate other in coexistence makes it possible for the observer to live in the domain of constitutive ontologies 
(Maturana 1988a).

Maturana argues that emotioning is at the base of all our actions in the praxis of living. The emotion of mutual acceptance (love) in Maturana's onto-epistemology is explained as a biological phenomenon. Indeed, Maturana speaks neither of feelings nor of kindness when referring to love.

"I speak of the emotion that specifies the domain of actions in which living systems co-ordinate their actions in a manner that entails mutual acceptance, and I claim that such operation constitutes social phenomena" (Maturana, 1988a).

Consequently, Maturana argues that rational arguments can change if emotions and moods change. In fact, we, human beings (according to our emotioning state) place ourselves in one or another ontological domain. In practice, what happens is that we 'swing' from one to another (constitutive ontologies $\leftrightarrow$ transcendental ontologies) domain. If the observer is taken by emotions and moods, where the other emerges as a legitimate other in the coexistence, it will be very natural to accept the different explanations about an experience of any observers as legitimate (living in the domain of constitutive ontologies). On the other hand, when the observer denies the emotion of mutual acceptance in coexistence, the unique explanations about an experience of any observers (the domain of transcendental ontologies) arise.

However, Maturana goes further, arguing that social phenomena (social systems) are such only if the emotions that specify domains of co-ordinations of action are based on the emotion of mutual acceptance. Indeed, in an organisational setting: even if an organisation which develops a product or service has a dynamic of coordination of actions among its employees, if the emotion of the personnel of that company is not one of mutual acceptance, then that organisation is not a social phenomenon. As we will see in the next sections, we argue that this could have great consequences when incorporating Maturana's onto-epistemology into Checkland's Soft Systems Methodology.

\section{A bridge for two views: Grafting Ontology of the Observer into the SSM process}

Having sketched the OoO, we will now proceed to substantiate our argument as to how to build a conversation between $\mathrm{OoO}$ and SSM. Our strategy consists of using the SSM process as the initial framework, to identify the SSM stages in which Maturana's OoO concepts can be 
grafted. This is illustrated in figure 1. As can be seen, we suggest the key elements that could help to build a bridge between the two approaches and in this way strengthen an SSM intervention and potentially overcome its limitations. The bottom part of figure 1 contains the OoO concepts (identified by a letter): (a) Recurrent interactions in mutual acceptance (social system); (b Notion of organisation; (C) Notion of structure; (d) Trigger structural change.

We propose that these concepts could be used as follows:

First, it is important to note that any act of pointing to something (for example defining what constitutes a situation considered problematic), implies an act of distinction. We can say that each stage of SSM can be regarded as an operation of distinction (Maturana \& Varela 1987:40) that separates something of interest from a given background. Any operation or act of distinction brings situations considered problematic from the criteria implied (implicitly or explicitly), in the Weltanschauung used to make that distinction. The Weltanschauung (in terms of Maturana's $\mathrm{OoO}$ ) corresponds to a criterion of distinction and a criterion of validation that make possible the way in which things are presented, especially what we consider as a problematic situation. Therefore, every time we perform one of the seven stages of SSM, we are performing acts of distinction.

\subsection{Recurrent interaction in mutual acceptance (a) in the SSM process}

According to Maturana, a social system only occurs if the components (living beings) are such that they participate in recurrent interactions in mutual acceptance. In fact, for Maturana, the emotion of love (or mutual acceptance) is the emotion that constitutes the social phenomenon. For this reason, sincerity in the dialogue is required, throughout the different stages (1-7) of SSM so that all Weltanschauungen are given the same importance and weighting for the people involved. The team (conforming the problem-solver system) should establish dialogues and develop them under the emotion of mutual acceptance. Stakeholders acting 'as if" they were under the emotion of mutual acceptance, will prevent the problem-solver system from 
operating as a social system.

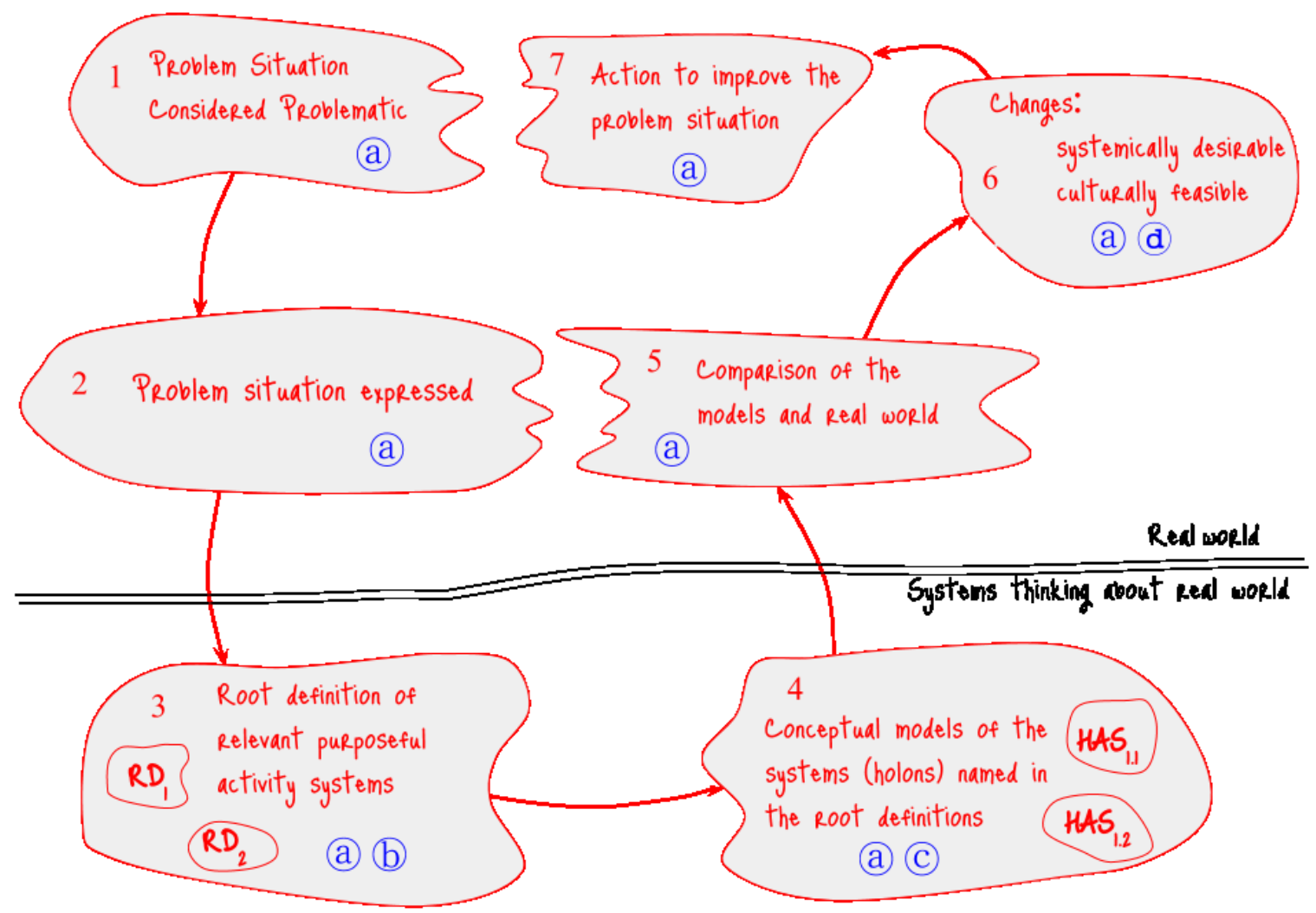

(a) Recurrent interactions in mutual acceptance (social system)

(b) Notion of organisation

(c) Notion of structure

(d) Trigger structural change

Figure 1. Enhancing SSM: OoO concepts grafted into SSM stages

A non-social system where mutual acceptance does not occur, will only consider the Weltanschauungen of the establishment and, of the people who have more power within the problem-solving team. We argue that one way to ameliorate SSM limitations is that in all stages of SSM, the dialogue should be promoted and arranged from the emotion of mutual acceptance. This is illustrated in figure 1 where the letter (a) (Recurrent interactions in mutual acceptance) indicates that this concept should be used to inform the way all the 7 SSM-stages are 
approached.

\subsection{Organisation and Structure (b), (c) and triggering systemically desirable and} culturally feasible (structural) changes (d)

The notion of organisation² (Maturana \& Varela 1987:47) letter (b) in figure 1 can be used specifically in SSM-stage 3, when a RD is proposed and, identity ('organisation' in Maturana's terms) is given to the HAS. Moreover, in SSM stage 4, the HAS models proposed are to be for concrete operational activities that must produce (generative mechanism) the situation or phenomenon that takes place in the real world. In Maturana terms, this corresponds to the notion of structure (Maturana \& Varela 1987:47) letter (C) in figure 1 that specifically constitutes a system of human activities that made its organisation (described in the RD) real. In effect, this illustrates the fact that there may be more than one structure (related operational activities) that can fit into and RD description. SSM literature corroborates this when it states that an RD encapsulates the definition of one or several possible HASs (Checkland and Tsouvalis, 1996).

Another interesting aspect that we can take from the $\mathrm{OoO}$ is the notion of structure-determined system. That is, the assertion that a system only does what structure allows it to do it; structure being those components and concrete relationships that made its organisation real. In an SSM intervention context, any model of HAS can do what its structure (stakeholders involved in operational, monitoring and control activities and the relations between them) allows them to do. The dynamics of interactions will define what is and what is not possible to do in the real world in the form of a structural coupling. From this point of view, systems are closed systems since the perturbation of the environment does not determine what happens with/within the system namely, the dynamics of interactions between their elements. Only the structure of the system can determine what occurs in it. Furthermore, a structural change occurs either as a change triggered by interactions coming from the environment or as a result of its internal

2 For an account of this concept please see beginning of section 3. 
structural dynamics.

Therefore, from an OoO standpoint, a HAS is regarded as a closed system so any change that we want to make in a HAS it will be directed in the form of a perturbation; the system will respond to this according to its structure. In this way, when we reach SSM stage 6, the changes that are systemically desirable and culturally feasible may trigger structural change (letter (d) in Figure 1) in the state of the HAS and it will respond according to its structure. In effect, the common metaphor of viewing learning as a way of 'transmitting' a set of instructive interactions to a (closed) system is certainly false (Maturana \& Varela 1987:196). This will have clear consequences when implementing SSM' 6th phase (take action): when the team of facilitators (intervening to bring some improvements to the situation) proposes a systemic intervention this can only trigger defined changes in the structure of the HAS itself.

\subsection{The ethics implications (from the OoO) of SSM measures of performance}

In order to evaluate and manage purposeful systems (modelled in stage 4 of SSM), Checkland proposes three criteria (three 'Es'): efficacy, efficiency and effectiveness. He later added two 'Es': ethics and elegance as two additional criteria that can be applied in particular circumstances (Checkland and Poulter, 2006:43). Checkland's ethics criterion responds to the (very general and/vague) question: Is this a morally correct transformation?

From the perspective of the OoO, the ethical criterion goes deeper, beyond 'moral' general statements. It aims to surface ethical concerns by questioning about the full consequences of the transformation encapsulated in the RD and embodied in the SSM conceptual model proposed. The OoO ethics questioning will be directed on to whether the set of the activities and relationships between these activities is favourable/not favourable and contributes/does not contribute to a dynamic interaction of mutual acceptance. That is to say that, from an $\mathrm{OoO}$ stance, the question to formulate is: "does the transformation promote or help to restore or cultivate dynamics of interactions based on the emotion of love?' In our proposed framework for an SSM intervention, this is illustrated by emphasising the concept of 'recurring interactions in mutual acceptance' along all SSM stages as shown in figure 1.

Looking at all SSM stages, it is worth noting that this criterion must carefully guide the stage 
6, when discussing systemically desirable and culturally feasible changes to be implemented. SSM Stage 6 is dialogue stage and this criterion must guide the dialogue that explores whether the proposed changes in the conceptual model favour the development and the stability of a HAS as a social system in structural coupling with its environment. However, according to the $\mathrm{OoO}$, to try to propose systemically desirable and culturally viable changes to a problematic situation (as expressed in the transformation) is not enough. We need to introduce a metatransformation that gives a deeper meaning to the transformation, a meta-transformation that will uplift the transformation from a non-social HAS into a social HAS.

Hence, grafting the OoO in the SSM process implies going in search of a genuine vocation that seeks to alleviate (and possibly dissolve) problematic situations. At the same time, it implies understanding that we interact with closed systems (HAS). Therefore, we will only be able to produce new dynamics of interactions by triggering structural changes. And most importantly, this is only possible if the facilitating team (and the rest of the parties involved) operates from mutual acceptance in the situation considered problematic (stage 7, letter (a) in figure 1).

\subsection{Orthogonal/no-confirmatory encounters: Stages 6 and 7 of the SSM intervention}

In order for the dialogue to move within relational dynamics of mutual acceptance, the dialogues and conversations must be such that the work team becomes an agent that triggers structural changes (that allow configuring new relational dynamics between those involved in the problem situation), in order to move towards a structural drift, characteristic of social systems. Maturana calls this type of interaction or encounters with the other, an "orthogonal" or "non-confirmatory" encounter (Maturana \& Pörksen, 2004: 114). An encounter has a noconfirmatory nature when it does not aim to confirm or reinforce those relational dynamics that characterise a non-social system. In other words, non-confirmatory interactions are interactions that cause structural changes where the relational dynamics result in mutual acceptance. Consequently, the dialogues should avoid "confirmatory" encounters, that is, "agonal" encounters. These interactions trigger those involved in a situation considered problematic, so that the same dynamics of interactions are preserved. This leads to the continuation of their unaltered relational drift. Thus, preserving the identity of the non-social system.

Developing a capacity to produce "non-confirmatory" interaction dialogues requires a learning 
process that gives rise to a systemic wisdom. Wisdom, as we understand it, is an acute capacity for reflection that is willing to abandon those convictions or certainties that prevent a holistic perception of specific situations. In this way, direct support is required in order to structure the debate or dialogues based on the emotion of love.

Consequently, from an OoO stance, the question will be: how can we (as part of the team of facilitators) support the development of mutual acceptance in the situation considered problematic and, cultivate sustainable new dynamics of interactions between the actors involved? In order to structure the debate around "confirmatory" and "non-confirmatory" interactions (and to find a way forward implementing the set of systemically desirable and culturally feasible changes), a device comprising a cylinder of an infinite ${ }^{3}$ number of Weltanschauungen is proposed.

\section{Findings on grafting the $\mathrm{OoO}$ on to the SSM intervention process}

In this section, we summarize our findings and the initial implications of grafting HM's OoO ideas into the SSM 7-stages process. We have organised our findings as follows: Firstly, we discuss the importance of the notion of social systems in Maturana's terms and its potential benefits to the SSM process. Secondly, we discuss the implications of Maturana's view on ethics and how this can be used in an SSM intervention. Finally, we advance a practical device: a 'Cylinder of infinities Weltanschauungen' to support the actions that trigger the changes, so that they are cultural feasibility and systemically desirable.

\subsection{Social and Non-Social systems: living in experience and in legitimate coexistence with others}

SSM as a systematic research process abandons the idea of seeing reality as a set of systems that must be modelled and find a solution to problem but instead aims to improve or alleviate situations considered problematic. In fact, SSM states that every phenomenon we encountered is complex, confusing and, dependent on the worldviews of the people involved. This is because they are created and recreated amidst continuous interaction of the different

\footnotetext{
3 Infinite, in theory but we know that in practice the number of Weltanschauungen will bounded by the number of stakeholders involved in the situation.
} 
participants. Phenomena are always a flow of events that give rise to the experience of temporality where events and ideas are intertwined (Checkland and Casar, 1986; Brocklesby, 2007). This is how ideas change as events bring us new experience. SSM exposes the observer and that is why phenomena are part of the flow of daily life (for OoO the flow or praxis of living) where ideas and events are intertwined (for the OoO, language, emotion and action are intertwined). As such, an inquiry about a phenomenon (considered problematic) involves organizing the exploration so that it is conceived as a "learning system". This is precisely what characterizes (according to SSM) a process of systemic inquiry and, not the simple observation of a "real world" comprising existing systems, such as with the hard systemic approach.

Therefore, if we accept that a particular phenomenon can be understood from different points of view, we should also accept that each of the particular understandings (which give rise to the HAS in an SSM intervention) are legitimate. Indeed, we should accept the Nietzschean premise that reminds us that there are no facts, only interpretations. In fact, we all have the truth or no one has it. This "truth" which needs to be re-signified, is certainly a "hermeneutic truth" and it is precisely what would allow us to establish the bridge between different observers who seek to understand a phenomenon in good faith.

If we reflect on what we are saying, we might be inclined to argue that what has been said so far puts us in the face of subjective chaos where everyone thinks whatever she/he wants and therefore, we are condemned to a sort of solipsism that prevents connection with each other. However, it can be argued the contrary occurs because it is precisely this experience which allows us to break away from a solipsism that will isolate us. This permanent form of being in the world is valid for every observer and is the bridge to inter-subjectivity. It is an invitation to joint reflection, to treat us the way we want to be treated, that is, as legitimate others. We hold that to understand the depth (experientially, not only in theoretical terms) of what we are saying, is to recognize the same phenomenal dynamics of human existence in each other.

\subsection{Maturana's ethics as criteria when building SSM models}

From an OoO point of view, any SSM systemically desirable and culturally feasible suggested changes should seek to favour the emergence and establishment of the social phenomenon in 
the proposed HAS to be implemented. In fact, the social phenomenon is characterized as such because it develops by virtue of mutual acceptance in a domain of coexistence-(understanding). A domain where it is not possible to exercise coercion and the dynamics of recurrent interactions seem self-motivated and spontaneous nourishes constitutive ontologies. Any action that denies a form of life in mutual acceptance favours transcendental ontologies. If there is no ethical concern, there is also no responsibility for the actions taken. Within that context, development of conceptual models or proposals for improved actions (made from a domain of transcendental ontologies) are supported by arguments, that ultimately, compel others. This is without using force, to do what "powerful" stakeholders want to do with them. In fact, the arguments used to convince others, often, refer to the use of transcendent elements as arguments in the explanations that justify a position (elaborated from transcendental ontologies, which are under an implicit cultural claim).

An ethical concern arises when the central theme refers to interaction with others, when actions we carry out impact on other human beings, that is, they have consequences. This is precisely when a breakdown occurs, one that affects people's rights in a community. Then, when (in an SSM intervention) designing HAS, we are committing actions because the design will result in a modified problematical situation. This happens by the action of introducing systemically desirable and culturally feasible changes. Maturana is clear in pointing this out:

"As a result, when somebody accepts our argument in favour of a particular ethical behaviour in a given social domain, we believe that our interlocutor is yielding to the transcendental, compelling power of our reasoning, and we do not see that he or she is doing so because, by accepting as legitimate the social domain in which the argument takes place, he or she enters the emotional domain of mutual acceptance in which the premises of that argument are valid." (Maturana 1988a).

Ultimately, if the changes made are such that the organisational community that carries out the HAS feels that they improve their capacity of coordination of actions (with mutual acceptance), we can say that the ethical problem is not a rational but an emotional issue.

When those involved in a problematic situation have different Weltanschauungen about it, Checkland maintains that an SSM proposal to improve the situation can be carried out in terms of systemically desirable and culturally feasible actions. Indeed, for Checkland, this is possible 
because those involved are willing to "accommodate" themselves to a set of proposed changes even though they do not necessarily agree with them. From this perspective, there is a 'willingness' to adapt, even if they do not share the same Weltanschauung. Our contention is that, from the $\mathrm{OoO}$ standpoint, this could lead to the appearance of unstable relational dynamics, that characterize a non-social system, in which the deeply ingrained Weltanschauungen, are either not revealed or are concealed and obscured through manipulative engagements and actions proper of coercive systems. Indeed, hypocrisy or insincerity is the source of all conflict and occurs when the stakeholders instrumentalize (through manipulation and subjection) the relationship by pretending to treat the other as legitimate in coexistence.

In our view, although SSM does acknowledge the need to give voice to the different views and provides some advice in the form of analysis 2 (social) and analysis 3 (political), Checkland $(1981,1999)$ it does not face the consequences of the underlying complexity of non-social systems (in $\mathrm{OoO}$ terms). In this regard, $\mathrm{OoO}$ position is rather radical: accepting accommodation means accepting that a HAS remains a non-social system and tacitly denies the legitimate divergence of Weltanschauungen. The $\mathrm{OoO}$ aims to change the relations of interactions in the structure of the organisation (HAS) so that the system that emerges as a result of these relationships is a social system.

Overall, SSM aims to understand a situation considered problematic and propose (in is sixth and seventh stages) systemically desirable and culturally feasible changes, so that organisations can improve. This poses a huge challenge and SSM will assemble a set of HAS that will eventually bring the improvements. However, from the $\mathrm{OoO}$, we asked ourselves the following questions: how could a situation considered problematic be improved, if in spite of the changes in the structure of the HAS (the set of models that the SSM intervention as assembled), the dynamics of interactions that maintain the distrust among human beings continues and is preserved? We noted that if a HAS changes its structure but retains those relation of interactions between components that foster and promote mistrust, it remains a non-social system organisation. In other words, there cannot be substantive improvement of a problematic situation, as long as the dynamics of interactions that make a non-social system are transformed, to the extent that they become interactions that sustain a social system. When there is no identity change (conservation of organisation), that is, when the situation considered 
problematic retains the identity of a non-social system, the systemically desirable and culturally feasible changes change a problem situation to another problem situation, without affecting the root of the problem.

\subsection{A cylinder of an infinite number of Weltanschauungen to facilitate structural changes from the emotion of love}

Figure 2 illustrates a cylinder with a 3-dimensional infinite number of Weltanschauung; and a 4-quadrant map with the two axes: "culturally feasible changes and / or systemically desirable changes ". We propose to use this device to strengthen stages 6 and 7 of the SSM intervention process as follows:

In stage 6 of SSM, a debate is proposed among the stakeholders, to take action to improve the problematic situation. What we propose is that this debate needs to take place in a space where relational dynamics (based on the emotion of mutual acceptance) should be paramount. This is a fundamental condition for the debate and reflection proposed to be a methodological contribution to the SSM intervention. The proposed device attempts to de-centre the Weltanschauung that have reached the stage 6 of SSM and is expressed in a corresponding RD. Therefore, the aim is to 'thematize' (explore/debate the context) the Weltanschauung through a discussion about the relevance of systemically desirable and culturally feasible changes. In practice, there will be changes classed as systemically desirable but not culturally feasible; others, systemically undesirable but culturally feasible: and, finally, changes that are neither systemically desirable nor culturally feasible. Each of these systemically desirable changes can be plotted in a two-dimensional graph (as shown in figure 2). 


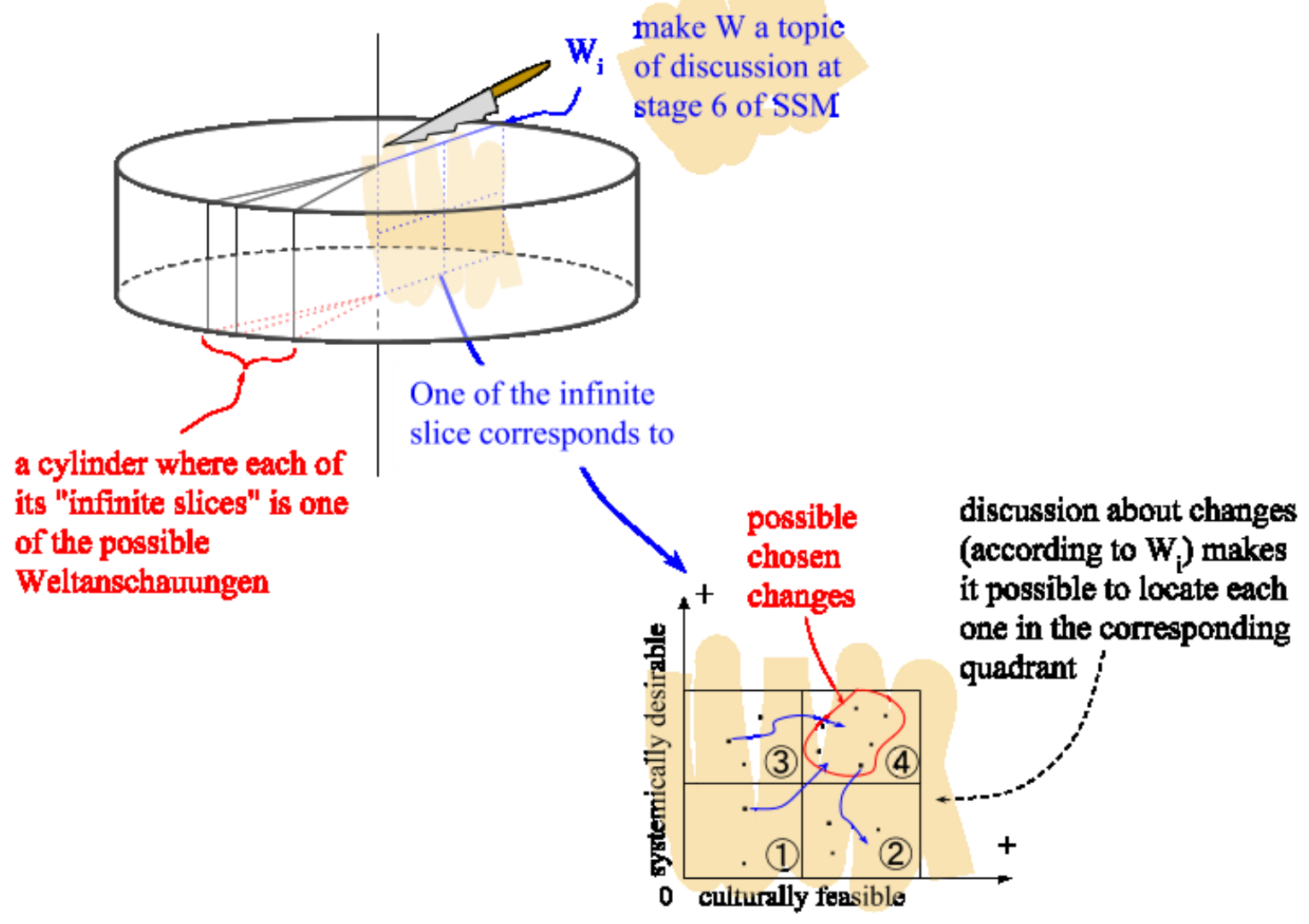

Figure 2. A cylinder of infinite (multiverse) number of Weltanschauung : Locating "culturally feasible changes and systemically desirable changes.

It is important here not to lose sight of the fact that the particular position of the changes in the four quadrants is based on a particular Weltanschauung $\left(\mathrm{W}_{\mathrm{i}}\right)$. However, if another Weltanschauung $\left(\mathrm{W}_{\mathrm{j}}\right)$ is considered legitimately, the proposed changes will move along the quadrants. Some will remain where they are but others will change quadrant. This is illustrated in the form of a cylinder of possible infinite Weltanschauungen (multiverse in terms of Maturana's OoO) and, by cutting a 'slice' in the cylinder at a particular point in time. Each of these slices are then located in one of the possible four-quadrant graphs, according to a given $\mathrm{W}_{\mathrm{i}}$ (see figure 2 ).

The idea here is that, armed with this device, we can then approach a second discussion (in mutual acceptance), about the pertinence of the particular location of each change in each quadrant. Discussion and reflection can begin by asking what Weltanschauung allows movement from quadrant one or more changes (points), for example, from quadrants 1,2 or 3 
to quadrant 4. Similarly, that question is also valid for those changes located in quadrant 4 to move to 1,2 or 3 . Therefore, if a new Weltanschauung is considered, a movement (of change proposals) will occur between the quadrants as shown in figure 2 (illustrated by the small arrows).

The cylinder is part of the explicit context where the dialogue will take place which explicitly invites the stakeholders to introduce themselves in a different way in front of the dialogue, namely, to interact with the others from the emotion of acceptance. Indeed, stakeholders must make an effort to suspend their judgments put their own reading forms in parentheses, which is a fundamental change of attitude, when considering the other as legitimate other with his or her Weltanschauungen.

It is worth to note that the conversation (facilitated by the proposed cylinder) between stakeholders are second-order experiences in the sense that they are reflections of the observers in his or her praxis of living in language about his or others praxis of living. Therefore, the different Weltanschauungen bring forth different domain of explanation and, consequently, different domain of actions. For this reason, any systemically desirable and culturally feasible change that is proposed, from a Wi (slice) will be located in some quadrant of the graph. However, the same proposed change, from another $\mathrm{Wj}$ (another slice), could be located in a different quadrant. The consequences of this second reflection with the cylinder of infinite Weltanschauungen, can lead to a revision of the CATWOE, the RD and the conceptual model of SSM stage 4.

\section{Concluding remarks and future research}

In this paper, we have reflected on the possibility of combining two systemic approaches: Checkland's SSM and Maturana's OoO. An enhanced 7-Stages SSM (that in many ways combined the best of the approaches) has been offered to cope with the apparent SSM limitations in tackling managerial and organisational problematic situations. The following are our final remarks advocating such enhanced mode of SSM application.

i. The aim of this paper is to encourage a conversation between these two approaches: 
Checkland's SSM and Maturana's ontology of the observer. We have done this by examining some theoretical basis of these two systems thinkers: The real world is for Maturana the "praxis of living". This is the primary experience where situations are perceived as problematic (discomfort, suffering, etc.). This resonates clearly with Checkland's position. In SSM terminology, the real word is a first-order linguistic domain, but "systems thinking about the real world" is a domain where the observer makes the explanations.

ii. The explanations are always experience but a second-order experience. Therefore, the systems thinking about the real world becomes a second-order experience as a reflection or an explanation about the first-order experience (the real world). Consequently, SSM explicitly separates these two domains because they are different phenomenal domains that do not intersect. This indicates that the phenomenon (real world) is not reducible to an explanation (encapsulated in a RD or a conceptual model). Maturana argues that living in the domain of constitutive ontologies prevents us from confusing these two phenomenal domains and therefore, this avoids a reductionist approach. From this point of view, that is, from the perspective of the OoO, SSM is constitutively a non-reductionist approach.

iii. In an action-research process, as is the case with the SSM, it is essential that emotion and states of mind are based on mutual acceptance. Then, it is necessary to incorporate spaces of dialogue (designed ad-hoc) where each of the participants are allowed to coordinate actions legitimately, with others in the dialogue. As these ontological domains imply a flexible domain of great plasticity that will increase the capacity of holistic understanding, the effort to transform ourselves into human beings makes us responsible for our doings.

iv. Every organisational intervention must be coherently performed (thinking, feeling and acting in the same direction), in correspondence with the emotion of mutual acceptance (empathy). Any SSM with the engrafted OoO should aim to restore the dynamics of trust and collaboration that allow repairing a system of non-social human activities, to transform it into social systems. Collaboration, for us, is cooperating (working together with others) with a shared purpose in a community. When the purpose is not shared, 
then it is a cooperation phenomenon but not collaboration (Jerardino-Wiesenborn, 2012).

v. In a participatory environment of mutual acceptance, that is, in a collaborative (not competitive) environment, the inclusion of all participants is favoured. When a participatory dialogue is required, one should explicitly not only favour but also welcome the many different domains in which we can live. This means "to predicate" (throughout the action-research project), about the path of co-existence in mutual acceptance, as the flexible mode of observation and holistic thinking (Maturana, 1997:145) associated with problematic situations.

vi. Finally, we are aware that the conceptual framework advanced here needs to be tested. To accomplish this, we propose this agenda for future research: (a) encourage SSM practitioners to submerge ourselves and experience Maturana's ideas and ethics by practicing them in a daily fashion; and (b) future research should seek to ascertain feasibility of the enhanced SSM framework in practice. Additionally, a set of constitutive rules should be designed that would warrant applicability of the enhanced SSM framework. In our case, we have already embarked in a project in which we plan to apply the framework to a series of real-world cases.

\section{References}

Brocklesby, J. (1995) Using SSM to identify competence requirements in HRM, International Journal of Manpower, Vol. 16, N. 5-6, p. 70.

Brocklesby J. (1997) Becoming Multi-methodology literate: an assessment of the cognitive difficulties of working across paradigms in Multimethodology, Mingers and Gill (eds.), John Wiley and Sons, Chichester.

Brocklesby, J. and Mingers, J. (2005). The use of the concept autopoiesis in the theory of viable systems. Syst. Res., 22: 3-9. doi:10.1002/sres.603

Brocklesby J. (2007) The theoretical underpinnings of soft systems methodology-comparing the work of Geoffrey Vickers and Humberto Maturana. Systems research and behavioral 
science 24(2): 157-169. Available at http://cepa.info/2800

Checkland, P.B. (1981, 1999) Systems Thinking, Systems Practice, Wiley.

Checkland P, Casar A. (1986) Vickers' concept of an appreciative system: a systemic account. Journal of Applied Systems Analysis 13: 3-17

Checkland, P. and Tsouvalis, C. (1997), Reflecting on SSM: The Link Between Root Definitions and Conceptual Models. Syst. Res., 14: 153-168.

Checkland, P.B. and Poulter, J. (2006) Learning for Action: A Short Definitive Account of Soft Systems Methodology, and Its Use for Practitioners, Teachers and Students, Wiley.

Dell, P. (1985) Understanding Bateson and Maturana: Towards a biological foundation for the social sciences. Journal of Marital and Family Therapy, 11: 1-20.

Flood, R.L., and Jackson, M.C. (Eds.) (1991) Critical systems thinking: Directed readings. Chichester: Wiley.

Jackson, M. (1982), The nature of soft systems thinking: The work of Churchman, Ackoff and Checkland, Journal of Applied Systems Analysis, 9:17.

Jackson, MC. (1991) Systems Methodology for the management Sciences, Plenum press, New York.

Jackson, MC. (1997), Pluralism in Systems Thinking and Practice, in Multimethodology, Mingers and Gill (eds.), Wiley.

Jackson, MC., (1999) Towards coherent pluralism in management science, Journal of the Operational Research Society 50, 12-22.

Jackson, MC (2003) Systems Thinking: Holism for Managers, Wiley: Chichester.

Jerardino-Wiesenborn, Bruno (2012) Diseño sistémico interpretativo de una racionalidad colaborativa a partir de la experiencia del software libre. Thesis of Master of Sciences in Industrial Engineering, Universidad of Santiago of Chile. Unpublished.

Ledington, P. and Donaldson, J. (1997). Soft OR and Management Practice: A Study of the Adoption and Use of Soft Systems Methodology. The Journal of the Operational Research Society, Vol. 48, No. 3 (Mar., 1997), pp. 229-240

Maturana H. R. (1970) Biology of cognition. Biological Computer Laboratory (BCL) Research Report BCL 9.0. University of Illinois, Urbana. $f$ Reprinted as the first section in 1980: 558.

Maturana H, Varela F. (1980). Autopoiesis and Cognition: the realization of the living. Reidel: Dordrecht.

Maturana H. R. \& Varela F. J. (1987) The tree of knowledge. The biological roots of human understanding. Shambhala, Boston \& London.

Maturana H. (1988a). Reality: the search for objectivity or the quest for a compelling argument. Irish Journal of Psychology 9: 25-82.

Maturana H. R. (1988b) Ontology of observing: The biological foundations of selfconsciousness and the physical domain of existence. In: Donaldson R.E. (ed.) Texts in cybernetic theory: An in-depth exploration of the thought of Humberto Maturana, William 
T. Powers, and Ernst von Glasersfeld. American Society for Cybernetics (ASC) conference workbook. Available at: http://cepa.info/597

Maturana H. R. \& Varela F. J. (1994) De Máquinas y seres vivos. Autopoiesis: la organización de lo vivo. Second Edition. Editorial Universitaria, Santiago de Chile.

Maturana H. R. \& Bunnell P. (1997) What is wisdom? Available at: http://www.sympoetic.net/Courses/502 Outline 2016 files/97\%20Maturana\%20\%26\%20 Bunnell\%20What $\% 20$ is\%20Wisdom.pdf

An abridged version of this paper was presented at the North American Association for Environmental Educators conference, July, 1997, under the title "What is Wisdom and How is it Learned?"

Maturana H. (1997) La Objetividad: Un argumento para obligar. Dolmen Ediciones. Santiago de Chile.

Maturana, H. and Poerksen B. (2004). From Being to Doing: The Origins of the Biology of Cognition. Heidelberg, Germany, Carl-Auer Verlag.

Maturana, H. and Dávila, X. (2008). Habitar Humano en seis ensayos de Biología-Cultural. Juan Carlos Sáez Editor, Colección Instituto Matríztico. Santiago de Chile.

Maturana, H. and Dávila, X. (2015). El Árbol del vivir. MVP Editores - Escuela Matríztica. Santiago de Chile.

Mingers, J. (1984). Subjectivism and soft systems methodology-a critique, Journal of Applied Systems Analysis. 11:85.

Mingers, J., (1997a) Multi-paradigm Multimethodology, in Multimethodology, Mingers and Gill (eds.), Wiley.

Mingers, J., (1997b) Towards critical pluralism, in Multimethodology, Mingers and Gill (eds.), Wiley.

Mingers, J. and Brocklesby, J. (1997) Multimethodology: Towards a framework for Mixing Methodologies. Omega, Int. J. Mgmt Sci. Vol. 25, No. 5, pp. 489-509, 1997

Munro, I. and Mingers, J. (2002) The use of multimethodology in practice-results of a survey of practitioners. Journal of Operational Research Society 59 (4), 369-378.

Paucar-Caceres, A. and Rodriguez-Ulloa R. (2007) 'An application of Soft System Dynamics Methodology (SSDM)'. Journal of Operational Research Society Vol. 58, 701-713, June 2007.

Reynolds, Martin (2004). Churchman and Maturana: Enriching the Notion of SelfOrganization for Social Design. Systemic Practice and Action Research, 17(6) pp. 539556. 